\title{
British - Czech Co-operation in a Mass Casualty Incident, Sipovo. From Aeromedical Evacuation from Bosnia to Discharge from Central Military Hospital, Prague
}

\author{
Lt Col DJ Vassallo \\ RAMC* \\ Consultant Surgeon
}

Hospital Squadron, 24 Armd Fd Amb, OP LODESTAR, Sipovo BFPO 538

Dr Z Klezl
PhD

Consultant Orthopaedic and Spinal Surgeon

Central Military Hospital Prague, U vojenske nemocnice 1200, 16902 Praha 6, Czech Republic

e-mail:rklez@lfl.cuni.cz

\section{Sqn Ldr ID Sargeant \\ RAF $^{\star \star}$ \\ Consultant Orthopaedic Surgeon}

Hospital Squadron, Sipovo

\author{
Col Dr J Cyprich \\ $\mathrm{PhD}$
}

Head Orthopaedic Surgeon

\section{Dr J Fousek \\ Consultant Orthopaedic Surgeon}

Central Military Hospital Prague, U vojenske nemocnice 1200, 16902 Praha 6, Czech Republic

SUMMARY: On Thursday 8 January 1998, a Czech Hip helicopter with 21 personnel on board crashed in Bos Krupa, northwest Bosnia, resulting in one of the largest mass casualty incidents involving peacekeepers in Bosnia since conflict broke out there in 1992.

Seventeen patients were airlifted from the scene to the British Hospital Squadron in Sipovo, central Bosnia for resuscitation and initial treatment. The next day, six severely injured patients underwent aeromedical evacuation to the Central Military Hospital in Prague. The role of the British Defence Medical Services in this incident was documented in the first article of this two part series. This second article highlights the role of the Czech medical services following aeromedical evacuation of these six patients, and closes the audit trail by documenting the patients' progress and final outcome in Prague.

\section{Introduction}

A Czech Hip Helicopter carrying 21 personnel crashed shortly after take off in Bos Krupa, northwest Bosnia on 8 January 1998. Seventeen of these casualties were resuscitated and underwent initial treatment at the British Hospital Squadron base in Sipovo. The next day, six severely injured patients were aeromedically evacuated to the Central Military Hospital in Prague. This article documents the treatment and final outcome of these six patients, and discusses the overlapping roles of the British and Czech Defence Medical Services in this incident.

Resume of initial diagnoses and treatment at Hosp Sqn Sipovo. Case Summaries of the six P1 \& P2 patients

Patient 1 the co-pilot, was seated on the right hand side of the cockpit, and took the brunt of the impact. His injuries consisted of closed fractures of the right tibia and right femur, disruption of the pubic symphysis and right sacroiliac joint, fractured first lumbar vertebra, seatbelt contusions to upper abdomen, bilateral lung contusions and haemothoraces. Bilateral chest drains were inserted. He underwent manipulation under

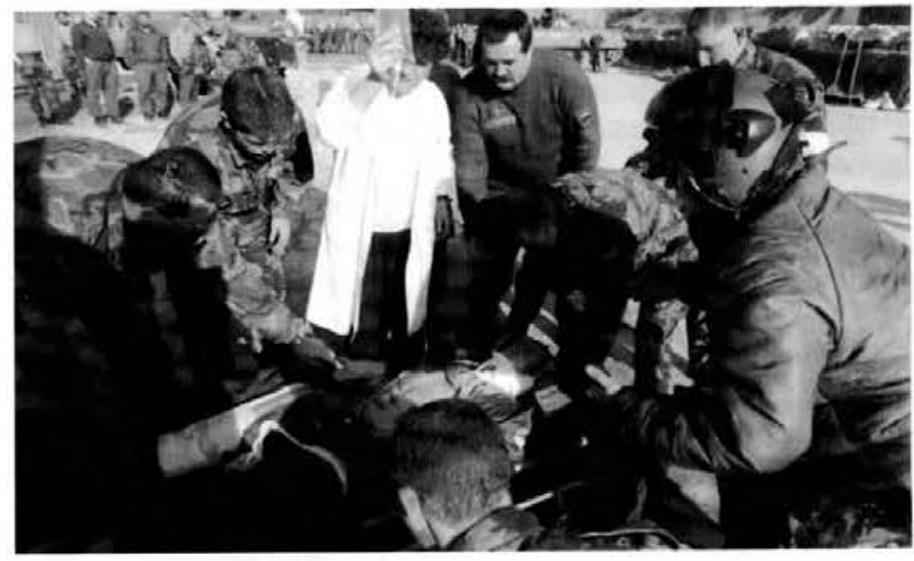

Fig 1. Resuscitation of Patient 1 at Bos Krupa by British and Czech medics.

anaesthesia of his tibial fracture and application of Thomas splint traction. His condition deteriorated overnight necessitating higher oxygen concentrations. For safe transfer he 
was electively intubated on 9 Jan 98, ventilated, and invasively monitored with arterial and Central Venous Pressure (CVP) lines (Fig 1).

Patient 2 was suspected of having a fracture of the right first rib, in addition to a definite fracture of the second rib and an underlying haemothorax. He was cyanosed at the scene. His condition improved with oxygen during transfer and stabilised once a chest drain was inserted in resuscitation. Sixteen hundred $\mathrm{mls}$ of blood was drained through this over the next 18 hours.

Patient 3 had a posterior dislocation of the right hip. He was transferred to the operating theatre for reduction under sedation within 30 minutes of arriving at Sipovo (Fig 2).

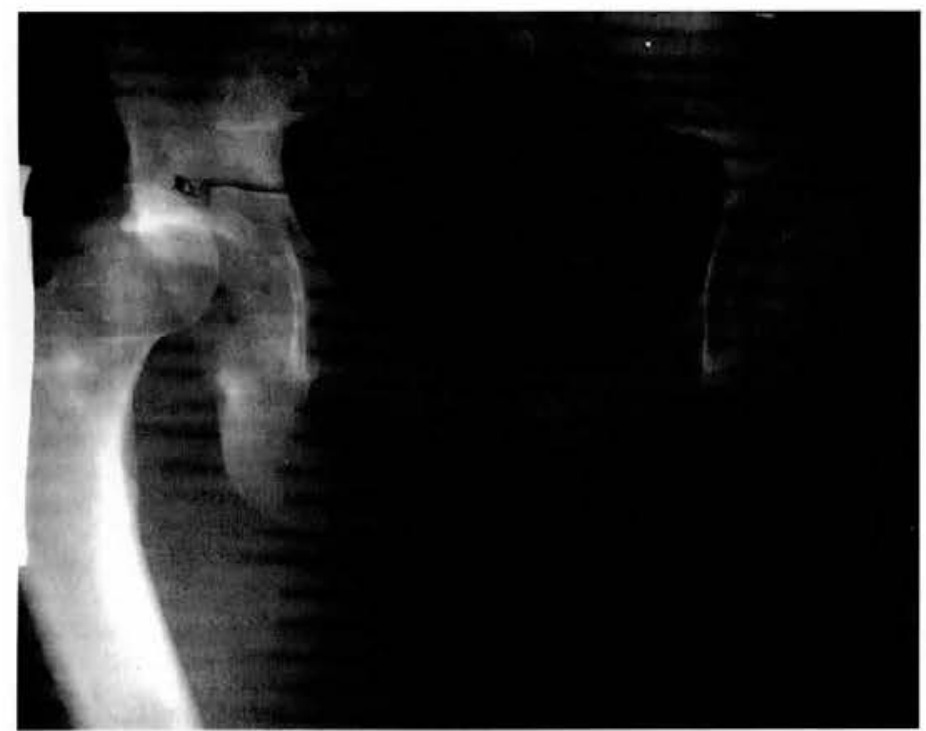

Fig 2. Dislocated right hip (Patient 3).

Patient 4 was suspected of having spinal injuries, but with no neurological deficit. He had seatbelt contusions over his right flank. X-rays confirmed that he had a Type II fracture of the odontoid peg (i.e., a fracture at the junction of the dens with the vertebral body), a fracture of the 12th thoracic vertebra, and a fracture of the right 12 th rib. He was maintained in rigid spinal immobilisation.

Patient 5 had a severely displaced fracture of the left distal humerus, a fracture of the surgical neck of the same humerus, marked seatbelt contusions over the abdomen and left chest, and a lateral scleral tear. His arm injury was treated by plaster immobilisation.

Patient 6 was diagnosed as having a minimal compression fracture of the 8 th thoracic vertebra, managed by strict bed rest.

\section{Aeromedical evacuation 9 Jan 98}

The six stretcher patients required aeromedical evacuation for definitive surgery or long term hospitalisation. A Czech Army Antonov aircraft with surgical and anaesthetic teams from the Central Military Hospital (CMH), Prague was tasked and arrived at Banja Luka airfield 1030hrs, Friday 9 Jan. Patients 2 - 6 were transferred to Banja Luka by Sea King and Chinook. In order to minimise the time in transit, Patient 1 , who had been intubated and ventilated, was transferred last in a SeaKing at $1358 \mathrm{hrs}$, accompanied by a full anaesthetic team. The Antonov left for Prague at 1455 hrs.
Arrival in Prague

The Antonov landed at Prague military airfield at $1800 \mathrm{hr}$ ग Friday 9 Jan 98 after a three hour flight. The six injured accompanied en route by the head anaesthesiologist from the $\mathrm{CMH}$, who organised the transfer to hospital. Transport priorêึies were clear: Patient No. 1 was brought in first by a helicopłer, landing on the helipad at the top of $\mathrm{CH} 2$ building (housing Emergency, Radiodiagnostics, Operating rooms, MRI). The other five patients were transferred by road in two ambulanç्心 $s$.

\section{Immediate management at $\mathrm{CMH}$}

At $\mathrm{CMH}$, a reception team of five anaesthesiologists, $\frac{5}{\sigma 6} \mathrm{wo}$

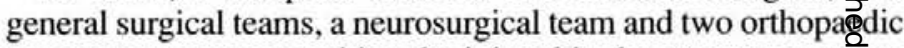
trauma teams were awaiting the injured in the emergency rowm. As the medical records (with accompanying translation) from the British Defence Medical Services were precise, and the X-rays of good quality, more specialised radiological studies were n⿳亠口冋’de immediately, except in the case of the most severely injo Patient 1 , who had been taken straight to the Intensive Care

\section{Specialised Radiological Investigations}

Patient 2 underwent urgent CT investigation of the thorax. Patient 3 underwent follow up chest X-ray.

Patient 4 underwent lateral tomography of the dens of $\mathrm{C} 2$, Nind CT-scanning of the T 12 fracture.

Patient 5 underwent urgent MRI to rule out disco-ligamenț injury at C6-C7 level.

Patient 6 had follow up X-rays of the thoracic spine to ruleciout major fracture.

\section{CMH Case Summaries and Final Diagnoses}

Patient 1

Diagnoses: Bilateral lung contusion with haemothoraces

Abdominal wall contusion

Right femoral diaphysis fracture

Right tibial diaphysis fracture

Disruption of the pubic symphysis and right sacroiliac joint

Fracture of first lumbar vertebra

Management: His first lumbar vertebral body fracture did ${ }_{\text {not }}$ require urgent $\mathrm{CT}$ scanning as there was no neurological deficit. In keeping with the modern management of polytrauma patiog he was the first one to be operated on to stabilise his right femiral and tibial fractures. Both were stabilised by uniplanar exte fixation in the Intensive Care Unit (Figs 3,4). When after 5 西ys his condition became stable, the L1 fracture was reduced 9 ind stabilised with posterolateral spinal fusion from T12 to L2. His general condition deteriorated on the 8th post injury day dus to severe lung infection leading to septic shock.

At this time it was evident that the planned exchange nailin the right femur and tibia would not be without significant ris of infection. The femoral external fixator was converted into planar configuration. X-rays confirmed that the femoral fracture was in satisfactory alignment and that the tibial fracture was So anatomically aligned. Since the disruption of the pîbic symphysis did not reach $2 \mathrm{~cm}$, this injury was tre conservatively. After a period in intensive care lasting 5 we $\mathrm{gss}$, his general condition improved sufficiently for him to $\mathbb{D}_{\text {be }}$ transferred to the orthopaedic trauma unit and mobilised. After 16 weeks in the $\mathrm{CMH}$ he spent a further 6 weeks in the miliọry rehabilitation unit. His recovery was complicated by $\mathbb{g}_{\text {he }}$ development of a deep vein thrombosis in the right lower leg क्ष̃ discharge from the rehabilitation unit, he was able to walk wi a slight limp with crutches, weight bearing more than $50 \%$, with both external fixators already dynamised. 




Fig 3. External fixation of right femur (Patient 1).

\section{Patient 2}

Diagnoses: Fracture of the right second and third ribs with underlying haemothorax. Non-displaced fracture of the left clavicle.

Management: This patient was managed conservatively without recourse to thoracotomy. The chest drain was removed on the sixth day, and he was transferred out of intensive care the next day. He was discharged from hospital twelve days after the crash, having had no complications.

\section{Patient 3}

Diagnosis: Posterior dislocation of right hip.

Management: He was put on skin traction for 4 weeks. After this he was placed in a walker progressing to crutches not bearing weight on the right leg for a further 6 weeks. He recovered well without any signs of structural changes in the right femoral head to date.

\section{Patient 4}

Diagnoses: Odontoid peg displaced fracture without neurological deficit

$\mathrm{T} 12$ fracture dislocation

Fracture of the right 12th Rib.

Management: This patient was repeatedly examined to confirm

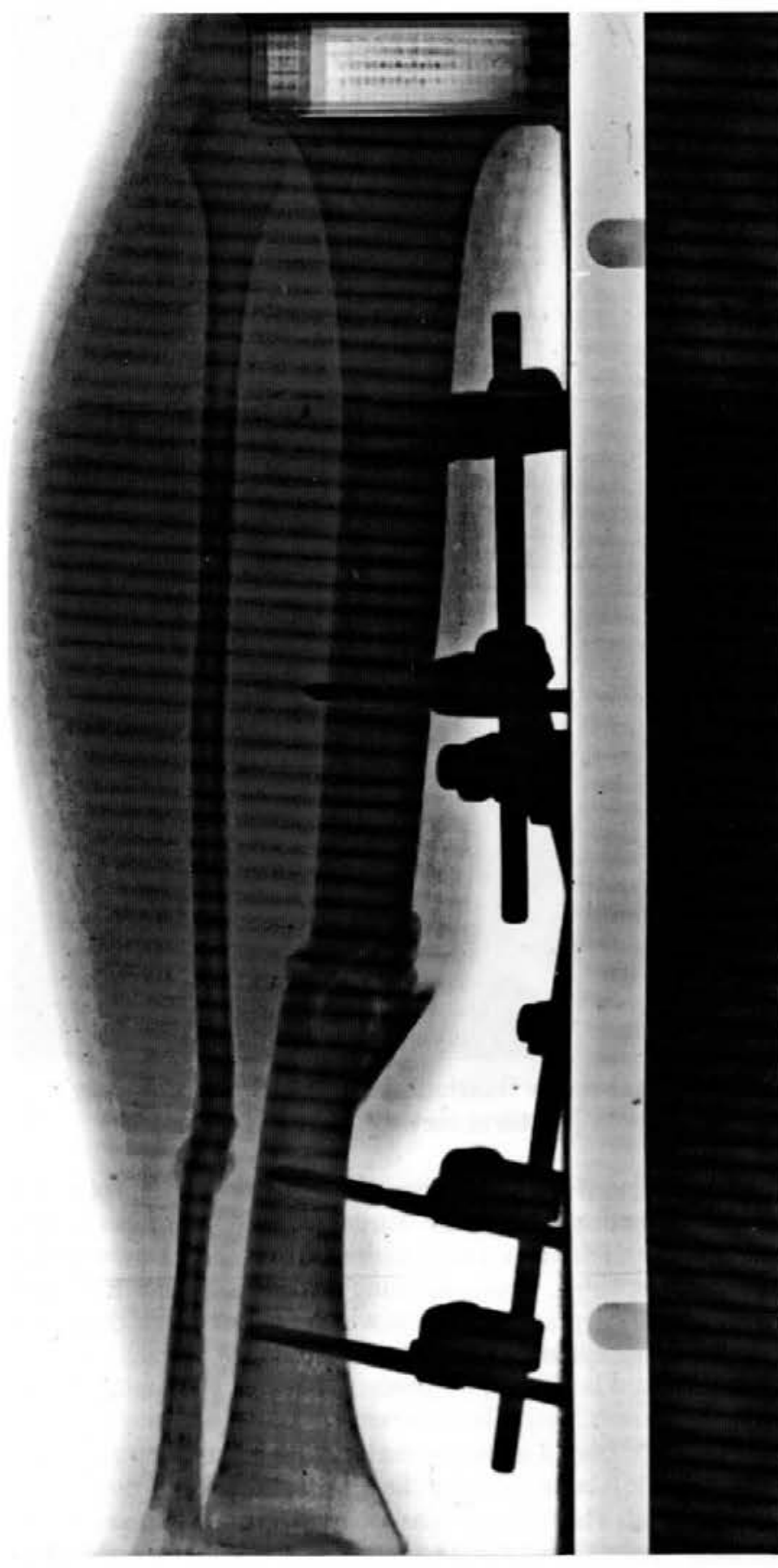

Fig 4. External fixation of right tibia (Patient 1).

that he remained neurologically intact. His stiff neck brace was changed to a Philadelphia collar. He arrived at $\mathrm{CMH}$ on a Friday, so surgery was planned after the weekend. This began with N endoscopic assisted intubation to prevent any further dislocation of the odontoid peg. The fracture was then reduced under 0 fluoroscopy using two image intensifiers simultaneously and two $\omega$ $\mathrm{AO}$ cannulated screws were placed across the fracture line (Figs 2 ? 5,6 ). The patient was then turned to the prone position on a spinal frame. His T 12 fracture was reduced and stabilised with $\stackrel{\oplus}{\rightarrow}$ an $\mathrm{AO}$ internal fixator, and posterolateral fusion from $\mathrm{T} 11$ to $\mathrm{L} 1 \mathrm{~T}$ was carried out (Fig 7). Cross link was used as this was demanded by the nature of the trauma (Fig 8). The fracture $\stackrel{\square}{\square}$ pattern was correctly identified from the initial films from $\stackrel{\triangleright}{\varnothing}$ Bosnia: the unilateral right 12 th rib fracture, with a T12 fracture, $₹$ indicated severe rotational forces at the time of the crash.

The patient was mobilised on the 5th post operative day in a응 Jewett hyperextension orthosis without any orthosis for the 


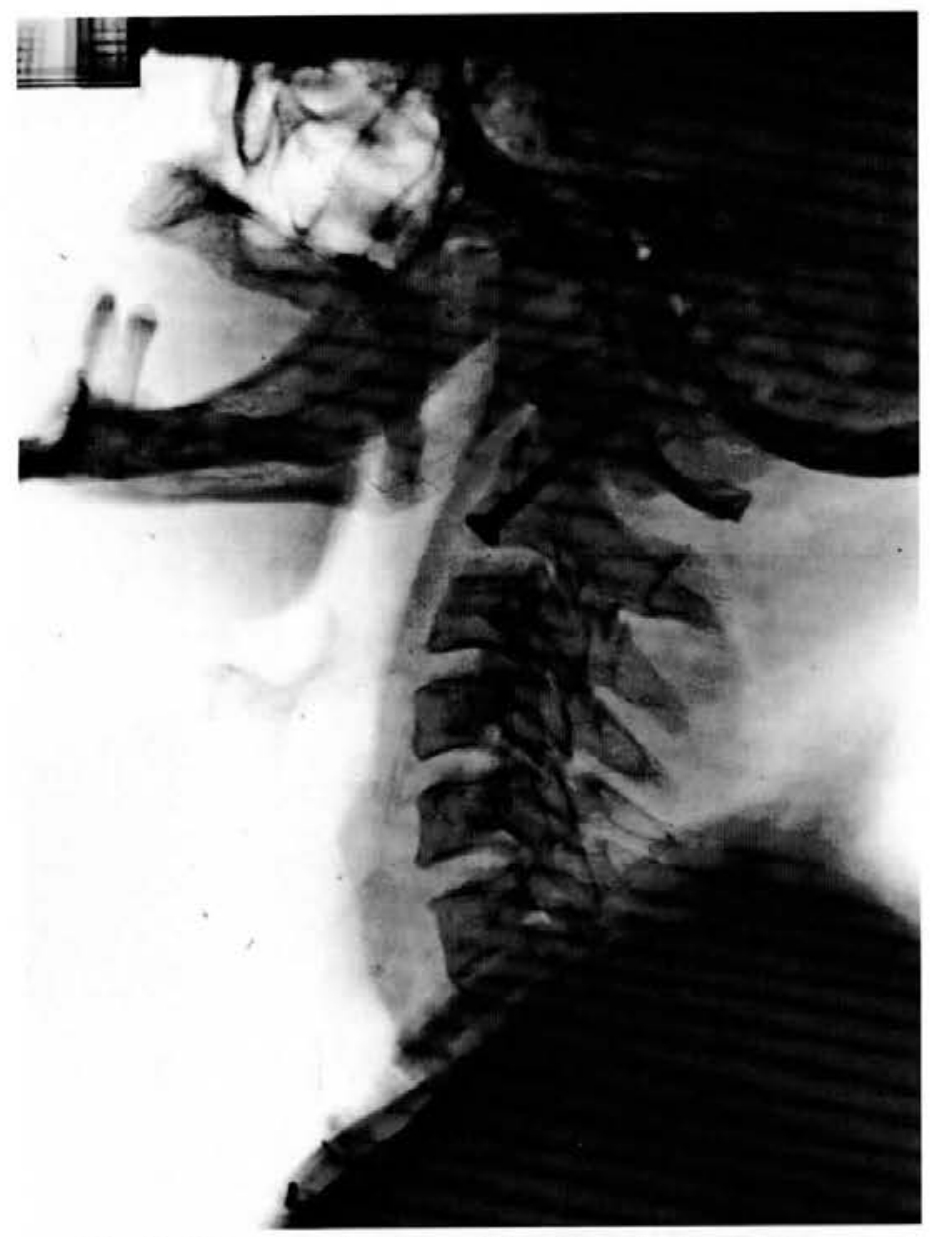

Fig 5. AO screw fixation of fractured odontoid peg, lateral view (Patient 4).

cervical spine. He was discharged from in-patient physical therapy 3 weeks after the surgery. His fractures healed uneventfully. He now has full range of movement of his cervical and lumbar spine, with morning stiffness being his only complaint. It is planned to remove the metal work from his thoracolumbar spine after 12-18 months.

\section{Patient 5}

Diagnosis: Displaced segmental fracture of right humerus.

Abdominal and chest wall contusion.

Management: This patient was operated upon on the day of transfer. Open reduction and internal fixation was performed. His arm was placed in a shoulder sling after the surgery and physical therapy was commenced. He has minor restriction of the range of movement in his right shoulder. The fracture has healed without complications.

\section{Patient 6}

Diagnosis: Soft tissue bruising to mid-thoracic vertebral region.

Management: His X-rays from Bosnia had been cautiously interpreted there as showing a minimal compression fracture of the 8 th thoracic vertebra. New X-rays were taken, and no clear fracture lines could be detected. A bone scan did not show any abnormality and since his mid thoracic pain rapidly resolved, he was discharged home 5 days after the transfer.

\section{Discussion}

The first article in this two part series described the crash in detail. It also discussed the mechanisms of injury and the role of the British Defence Medical Services in this incident (1).

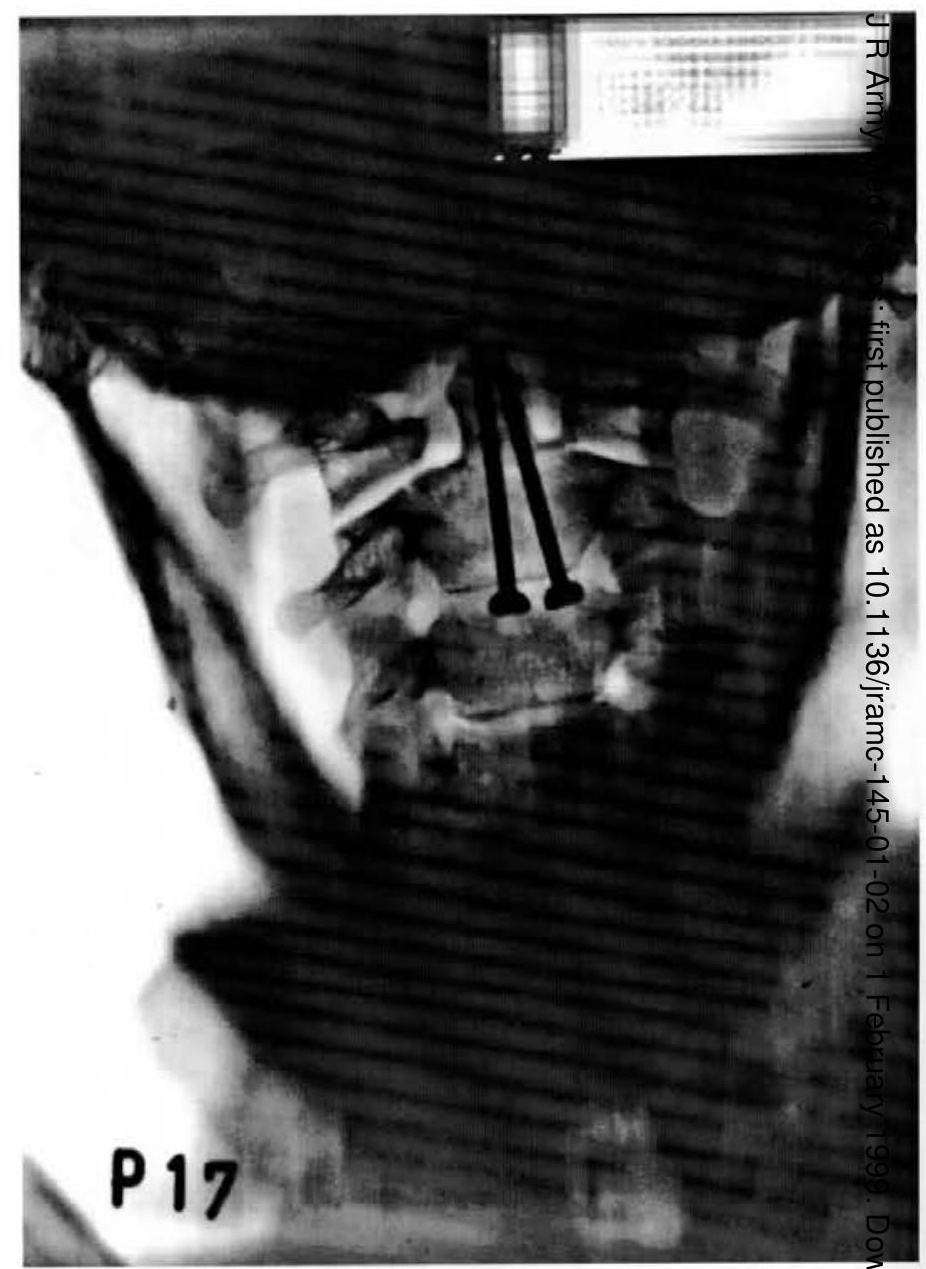

Fig 6. AO screw fixation, p.a. view (Patient 4).

Prior to deployment to Bosnia all British medical \&nit

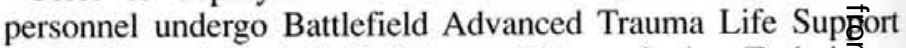
(BATLS), and Battlefield Advanced Resuscitation Techniçues and Skills training (BARTS), modelled on Advanced Tra满a Life Support (ATLS) training. This training is reinforced byintheatre refresher training programmes (2). The motto of BA $\underline{E} L S$ and BARTS is apt: "Deliver to the surgeon a live patient". 可he value of this training was illustrated by the efficient treatmeit of casualties throughout this incident from extraction from crashed helicopter to the resuscitation at the Hospital Squadion Sipovo, through to the aeromedical evacuation of six sevegely injured patients, including one on a ventilator, to Prague. The patient with the odontoid peg fracture (Patient 4 ) certainly ofyed his life to the care taken with cervical spine immobilisatiob as taught in BATLS and BARTS. Since 1997, Czech milifary doctors have also been trained along ATLS guidelines, thơgh there is as yet no equivalent of BARTS training for C military paramedics.

Once the patients had reached the definitive care facility of Central Military Hospital, Prague, their successful outcome opas determined by the skill and care of highly trained personnel filly equipped with the latest surgical equipment and intensive facilities.

Urgent internal fixation and stabilisation of the long bigne fractures in the polytrauma patient (Patient 1) was deepied necessary by both British and Czech surgeons for his optinal management, in keeping with established practice $(3,4)$. Bhis could only be performed in the setting of a base hospital. It $\$$ as purposely decided not to perform external fixation in Sipovg in the short time before aeromedical evacuation because it was this might compromise the definitive treatment in Prague. it 




Fig 7. Posterolateral spinal fusion T11 to L1 (Patient 4).

turned out, the planned internal fixation could not be performed due to the development of a chest infection and the risk of sepsis; the external fixation initiated on arrival in ICU had to suffice.

This helicopter crash coincided with the establishment of an email facility at Hospital Squadron Sipovo as part of the first telemedicine link for the British Defence Medical Services (5). Even though the casualties from this crash required aeromedical evacuation to a destination other than the UK, images of their Xrays were taken with an Olympus $\mathrm{C} 800 \mathrm{~L}$ digital camera (subsequently upgraded to a higher resolution Olympus C1400L), downloaded onto a laptop, and transmitted to the Royal Hospital Haslar by landline as e-mail attachments for radiological and orthopaedic opinion. The digitised image of the $\mathrm{X}$-ray of the odontoid peg fracture of Patient 4 is illustrated in our previous article (1), and a digitised image of the dislocated hip of Patient 3 accompanies this article (Fig 2). Sample X-rays and other images subsequently transmitted from Sipovo to Haslar using the high resolution Olympus $\mathrm{C} 1400 \mathrm{~L}$ digital camera can be viewed at the website of the Haslar Radiology Department (6).

Receipt of such images at Haslar prior to aeromedical evacuation could have facilitated the planning of definitive orthopaedic treatment had the patients been evacuated there. If the British team at Sipovo had known the telephone number and e-mail address of the orthopaedic surgeons at the $\mathrm{CMH}$ in Prague, then these images and relevant clinical details would have been transmitted there on the night of the helicopter crash, to facilitate similar planning.

This incident highlighted a deficiency in the planning for aeromedical evacuation from this multinational operational scenario: the main British field medical unit and the aeromedical squadron in Bosnia did not know the contact telephone numbers or addresses of base hospitals in countries other than the UK.

As a direct result of this crash, a Web page listing the postal and e-mail addresses (where available) and the telephone numbers of NATO base hospitals and deployed medical units has

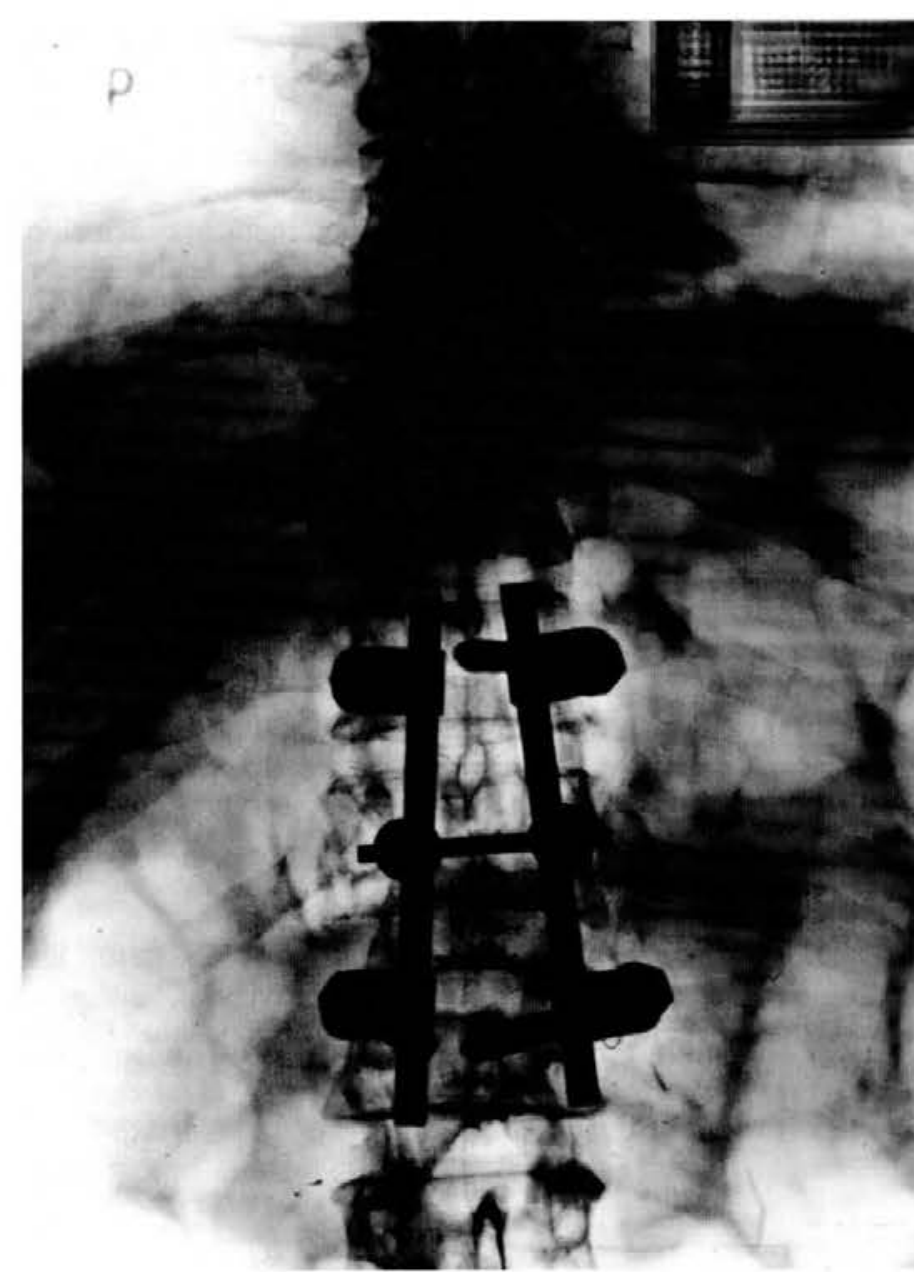

Fig 8. Spinal fusion with cross-link (Patient 4).

been compiled by the librarian at the Royal Hospital Haslar. This $\stackrel{2}{\overrightarrow{7}}$ is available for consultation by medical personnel worldwide via 윽 the internet (7). This should facilitate clinical co-operation in future multinational incidents, and this facility should be publicised in predeployment training.

This disaster serves as a model for military trauma care organisation, where highly trained field medical teams (Roles $1 \stackrel{2}{2}$ to 3 ) are responsible for proper first aid, triage, resuscitation and $\vec{\nabla}$ stabilisation of major injuries, and the Role 4 base hospital teams are responsible for definitive care of all injuries. Appropriate use $\dot{\overrightarrow{0}}$ of aeromedical evacuation to transfer patients to definitive care facilities, as in this instance, minimises the time spent in $\delta$ transferring critically ill patients and significantly contributes to a successful outcome.

Rapid access to definitive care, and prompt fracture $\rightarrow$ stabilisation in polytrauma patients, as shown in these cases, results in an improved outcome. Recovery is much faster if N multiple, less definitive operations can be avoided. These only $N$ serve to prolong treatment and are less effective medically and economically.

This incident is a unique example of co-operation between the Defence Medical Services of a NATO country and a future $\frac{\overparen{D}}{\mathscr{D}}$ NATO country in a mass casualty incident involving personnel of $\stackrel{\mathscr{S}}{?}$ both. It has promoted mutual liaison and understanding, and $\frac{T}{0}$ enhanced awareness of the training and preparedness of each $\frac{\text { P }}{\mathbb{D}}$ other's medical services. The Czech forces are actively reshaping $\frac{\rho}{\mathbb{D}}$ themselves prior to joining NATO (8), and it is believed that this $\frac{\Omega}{8}$ is their first documented instance of major medical co-operation with NATO.

This article has been compiled and revised by e-mail, through the contact established between the first and second authors at the 
time of aeromedical evacuation of the six patients to Prague. This is possibly the first time that such use has been made of the email to compose a multinational article for the Journal of the RAMC, which itself can now be contacted via the e-mail address of the RAMC Regimental HQ (rhq.ramc@clara.net).

It is not often that the final outcome of aeromedical evacuation to another country following an incident such as this helicopter crash is known: it is reassuring to know that the multinational peacekeeping troops in Bosnia have excellent medical cover from the front line back to base, wherever that may be.

\section{Conclusion}

This helicopter crash resulted in one of the largest mass casualty incidents involving peacekeepers in Bosnia since war broke out there in 1992, and provided a unique opportunity for international medical co-operation. The successful initial management of this incident by the British Defence Medical Services reflects very highly on the standard of training and preparation of British medical personnel. The high standard of definitive care received by the patients at the $\mathrm{CMH}$ Prague is a model for the military medical services of both countries.

\section{Acknowledgments}

To Dr George (Jiri) Brancik, Czech psychologist, for his sterling assistance as a colleague, as an interpreter, and as a liaison officer between Hospital Squadron and the Czech authorities during this incident.
REFERENCES:

1. Vassallo DJ, Sargeant ID, Sadler PJ, Barraclough C? BHATt BM, WILCOCK AC, Mass Casualty Incident at Hospit Squadron Sipovo, Bosnia following a Czech Hip Helicopter Crash, 8 Jan 1998. J R Army Med Corps 1998; 144:61-66. \$े

2. Riley B, Mahoney P. Battlefield Trauma Life Support: I $\frac{\delta}{5}$ use in the Resuscitation Department of 32 Field Hospit: during the Gulf War. Milit Med 1996; 9:542-546.

3. HARDin GT. Timing of fracture fixation: a review. Ortho Rev 1990; 19:861-867.

4. BeHRMAN SW, Fabian TC, KudSK KA, TAYLOR JC. Improv영 outcome with femur fractures: Early vs Delayed Fixation. Trauma 1990; 30:792-798.

5. Vassallo DJ, Buxton PJ, Kilbey JH, Trasler M. The Firot Telemedicine Link for the Defence Medical Services. $J \stackrel{\mathscr{R}}{Q}$ Army Med Corps 1998; 144:125-130.

6. Buxton PJ, KILBEY JH. Royal Hospital Haslar Radiolog Department. (Website: http://ourworld.compuserve.con homepages/xray_haslar).

7. RowE M. NATO Medical units contact addresses. (Website http://www.rowe.dircon.co.uk/medical/nato.htm).

8. ReEd Q. Country briefing - The Czech Republic. Czech forces reshape for NATO entry. Jane's Defence Weekly 199 (20 May); 29(20):18-27. 